T. Ludian, L. Wagner

Clausthal University of Technology, Institute of Materials Science and Engineering, Agricolastr.6, 39768 Clausthal-Zellerfeld, Germany

\title{
MECHANICAL SURFACE TREATMENTS FOR IMPROVING FATIGUE BEHAVIOR IN TITANIUM ALLOYS
}

\begin{abstract}
Mechanical surface treatments such as shot peening or ball-burnishing induce high dislocation densities and residual compressive stresses in near-surface regions. In addition, the surface roughness is changed. Micro-hardness and residual stress-depth profiles are evaluated in Ti-6Al-4V as a function of the Almen intensity being the main process parameter in shot peening. In the finite life regime, residual compressive stresses are shown to drastically increase the fatigue life by retarding crack growth from the surface into the interior. However, in the HCF regime a shift in crack nucleation site occurs from the surface to subsurface regions where residual tensile stresses balance the outer compressive stress field. Therefore, the tensile mean stress sensitivity of the fatigue strength which can largely vary in Ti-6Al-4V needs to be taken into account in order to understand the observed differences in HCF responds to shot peening.
\end{abstract}

Keywords: shot peening, residual stresses, crack nucleation, micro-crack propagation

\section{INTRODUCTION}

Mechanical surface treatments such as shot peening, mechanical polishing or ballburnishing can be utilized to improve the fatigue life of metallic materials [1]. In most cases the following three surface properties namely surface roughness, degree of cold work or dislocation densities and residual stresses are modified. Since the fatigue life is simply the sum of the numbers of cycles to crack initiation and those of crack propagation, modifying surface properties using these treatments may well have contradictory effects on fatigue life.

\section{EXPERIMENTAL AND RESULTS}

\section{Surface Layer Properties}

Figure 1 illustrates the main changes in surface layer properties after shot peening of Ti-6Al-4V [2]. As seen in Figure 1a, the surface roughness drastically increases during shot peening if compared to an electrolytically polished reference. The half-width 
interference line-depth profiles indicate the variation in the gradients of total dislocation density as the air pressure in peening is varied (Fig.1b). Residual compressive stresses are measured with penetration depths being a function of the air pressure or intensity of shot peening (Fig.1c).

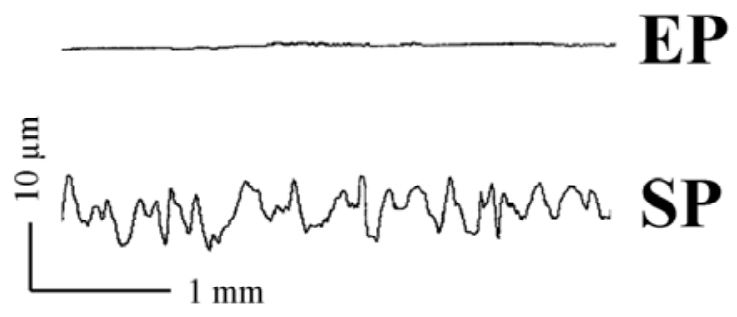

a) Surface roughness

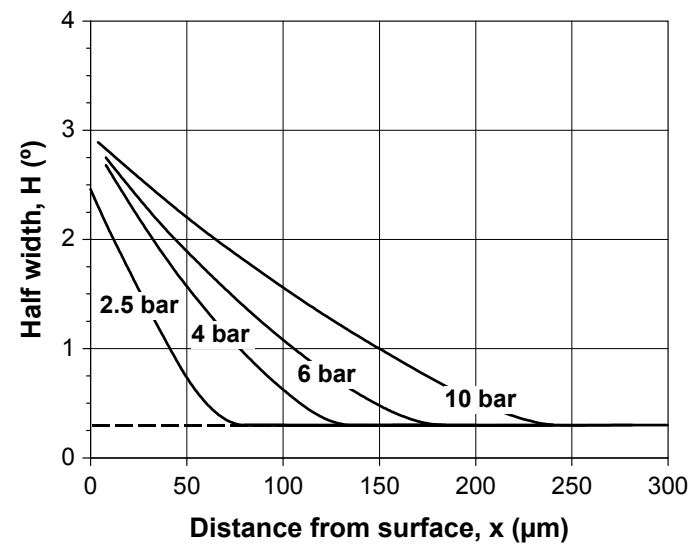

b) Dislocation density-depth profiles

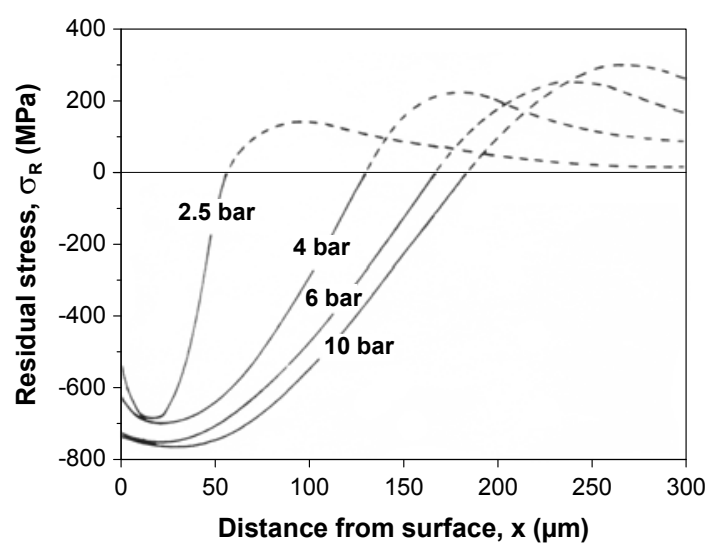

c) Residual stress-depth profiles

Fig.1. Process-induced changes in surface layer properties

These changes induced by mechanical surface treatments are not necessarily stable (Fig.2). For example, the high surface roughness can be reduced by additional polishing (Fig.2a). While the high dislocation density is thermally quite stable (Fig. 2b), residual 
stresses easily relax at elevated temperatures (Fig.2c) [3]. Annealing at temperatures above $650^{\circ} \mathrm{C}$ are necessary to reduce this high dislocation density (Fig.2b) which eventually leads to recrystallization and phase transformation from the lamellar to an equiaxed microstructure in Ti6Al-4V [4].

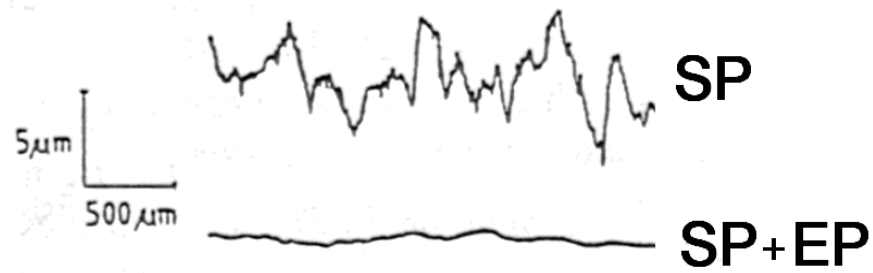

a) Polishing after shot peening

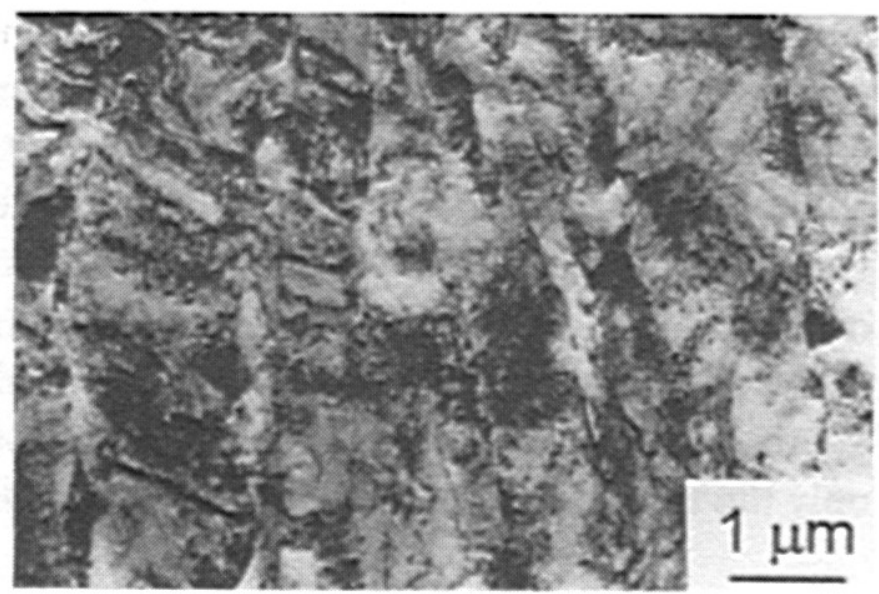

b) Dislocation density (TEM) after stress relief at $600^{\circ} \mathrm{C}$ for 1 hour

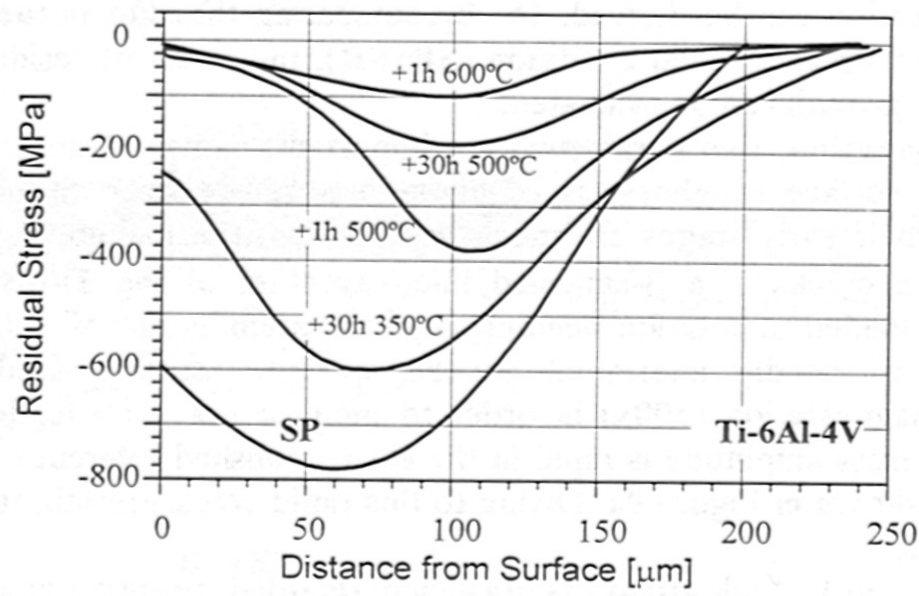

c) Residual stress-depth profiles after various heat treatments

Fig.2. Effects of additional treatments on surface layer properties 


\section{Effects on Fatigue Life}

Figure 3 illustrates the various stages in fatigue life of a component including the crack-free stage where mainly cyclic plastic deformation (cyclic hardening and/or cyclic softening) characterizes the fatigue state followed by fatigue crack nucleation, microcrack and macro-crack propagation until final fracture. Obviously, mechanical surface treatments will mainly affect the crack nucleation and micro-crack propagation stages while macro-crack growth as well as final fracture will not be influenced by mechanical surface treatments [5].

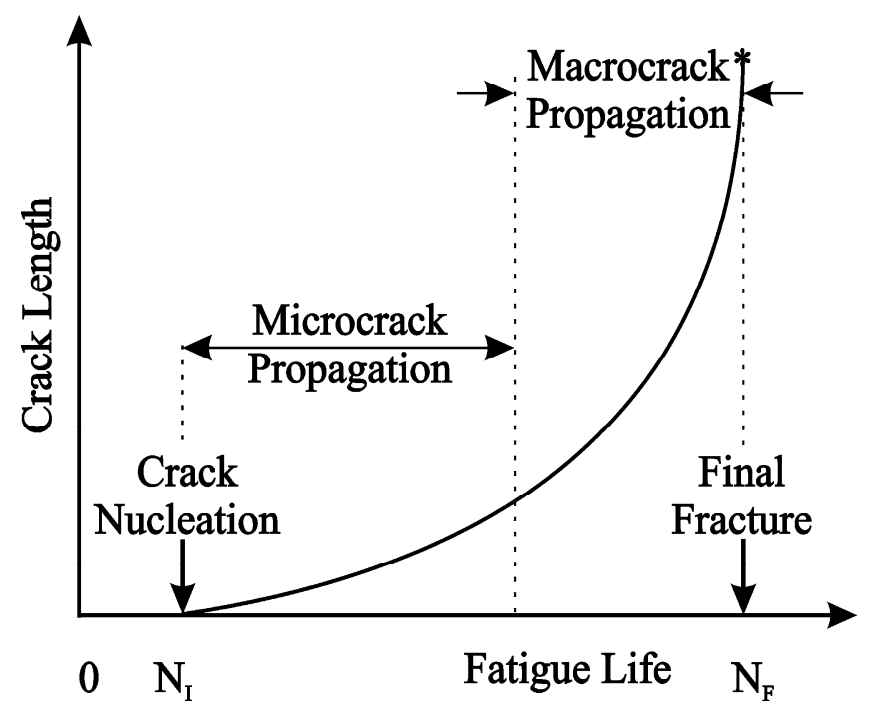

Fig.3. The various stages in fatigue life

In Figure 4, the micro-crack growths of condition EP (Fig. 4a) and of condition SP (Fig. 4b) can be compared. Clearly, crack growth in EP is much faster than in SP.

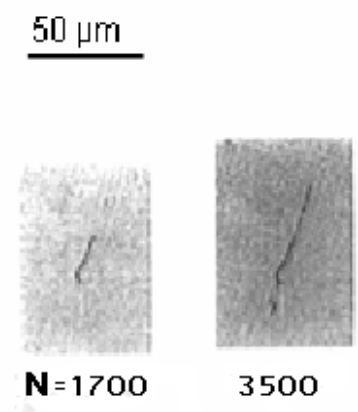

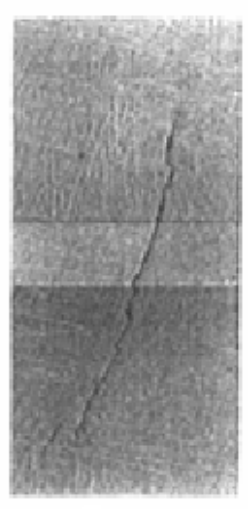

5200

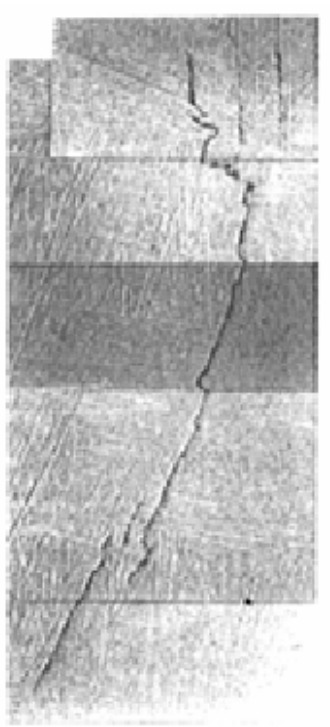

6900 


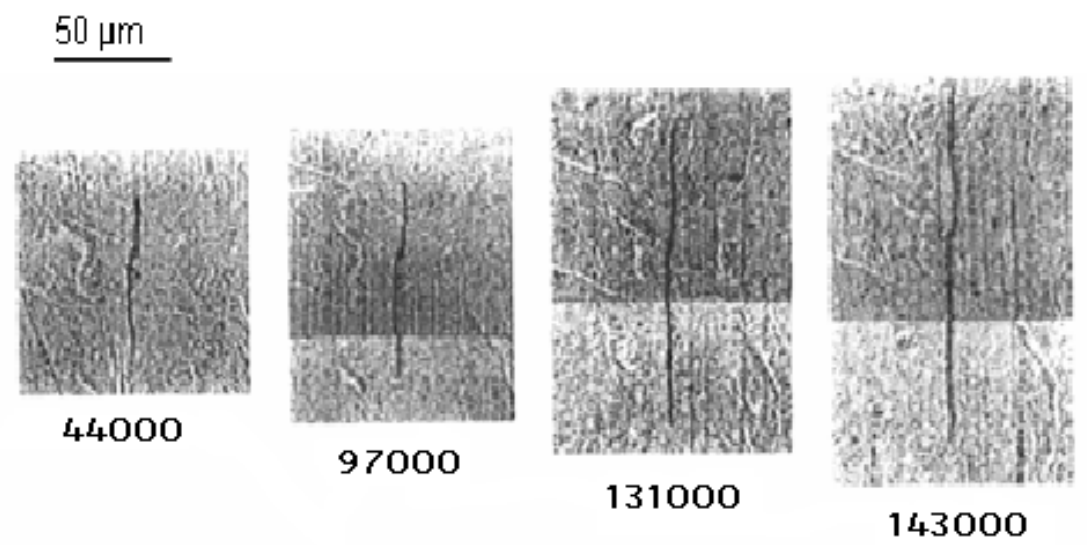

b) Shot peened (SP)

Fig.4. Micro-crack growth $\left(\mathrm{R}=-1, \sigma_{\mathrm{a}}=775 \mathrm{MPa}\right)[6]$

The corresponding da/dN curves from the data of a number of micro-cracks are plotted in Figure 5. Crack propagation rates at the same crack length or amplitude of the stress intensity factor are drastically retarded in SP, but accelerated in SP+SR when compared to EP. The difference in crack propagation rates between curves SP and $\mathrm{SP}+\mathrm{SR}$ is caused by residual compressive stresses in SP, whereas the difference between curves $\mathrm{SP}+\mathrm{SR}$ and $\mathrm{EP}$ is due to the high dislocation density in $\mathrm{SP}+\mathrm{SR}$ [6]. The inferior behavior of SP+SR compared to reference EP is caused by the negative influence a high dislocation density, and hence low residual ductility, has on crack propagation resistance.

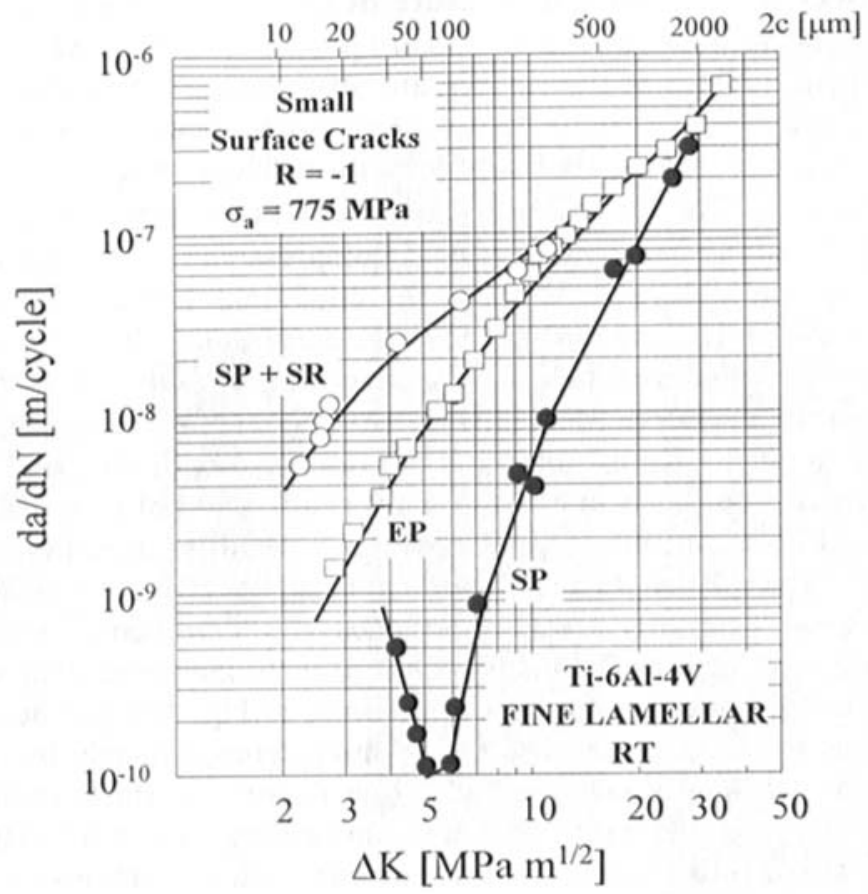

Fig.5. da/dN curves of the various conditions in Ti-6Al-4V 


\section{Effects on HCF strength}

With a decrease in stress amplitude, often a shift in crack nucleation site from the surface to subsurface regions in mechanically surface treated specimens of titanium alloys is observed (Fig.6).

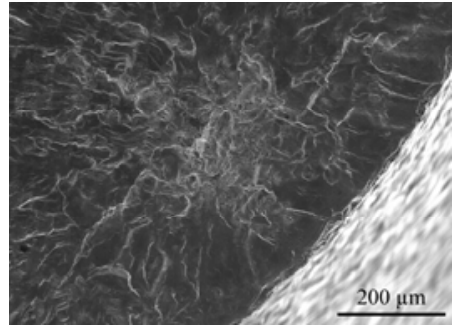

a) $\mathrm{Ti}-2.5 \mathrm{Cu}$

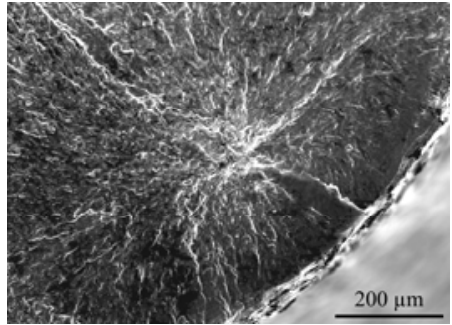

b) Ti-6Al-4V

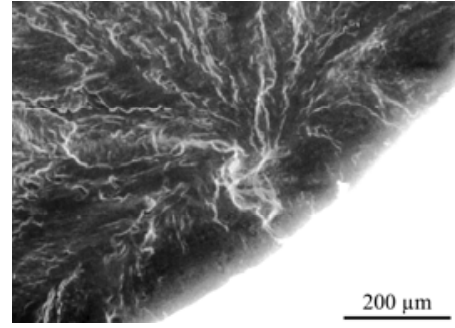

c) TIMETAL LCB

Fig.6. Subsurface fatigue crack nucleation in shot peened titanium alloys [6]

From the result that the depth of the crack nucleation site can be correlated with the Almen intensity and the rolling force in shot peening and ball-burnishing, respectively (Fig.7), it was argued that residual tensile peak stresses must be present in these regions balancing the outer compressive stress fields (Fig.8, see distance X).

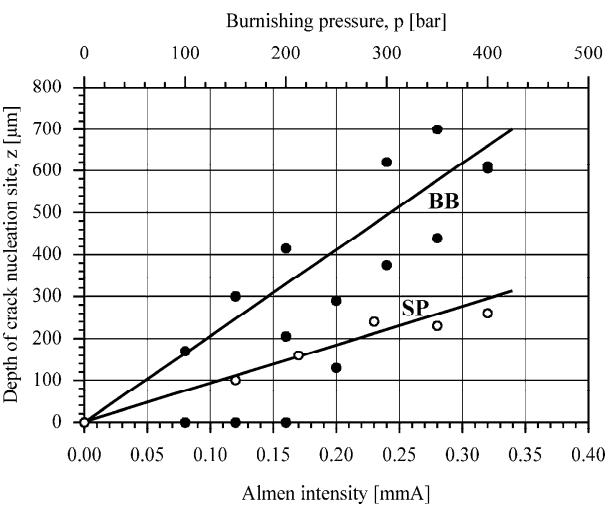

Fig.7. Depth of crack nucleation site

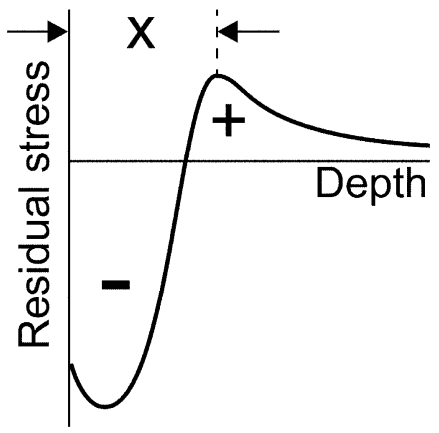

Fig.8. Residual stress-depth profile

\section{Influence of Mean Stress Sensitivity}

Since fatigue crack nucleation in shot peened or ball-burnished specimens tested in the HCF regime occurs in regions of residual tensile peak stresses (Fig.8), the tensile mean stress sensitivity of the fatigue strength needs to be taken into account in understanding the HCF response to mechanical surface treatments. In addition, the environmental sensitivity of the fatigue strength is important since subsurface cracks nucleate under quasi-vacuum conditions. This is in contrast to the electropolished reference where cracks nucleate at the surface and thus, the test environment directly affects fatigue crack nucleation and crack growth. In the following, results on duplex microstructures of Ti-6Al-4V which differ largely with regard to the mean stress sensitivity of their fatigue strengths will be presented and their fatigue performance after shot peening be contrasted. 


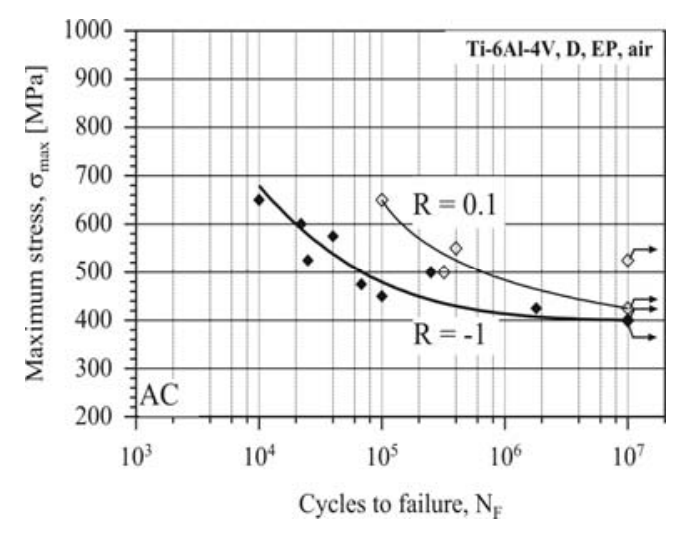

a) Duplex/AC

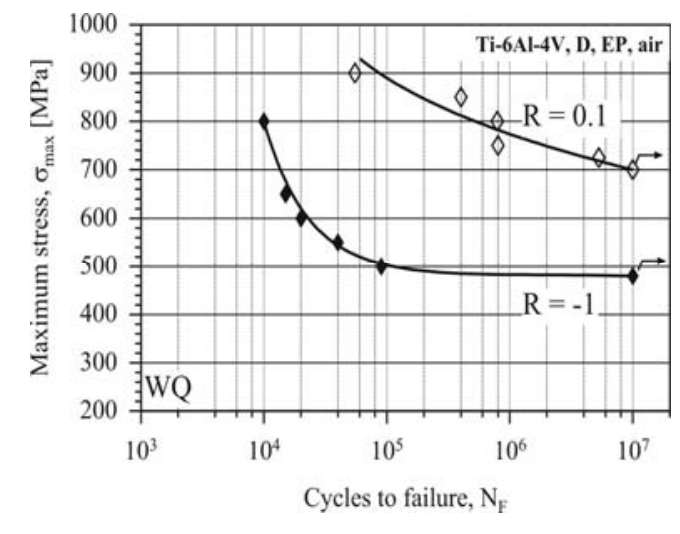

b) Duplex/WQ

Fig.9. Fatigue performance of duplex microstructures of Ti-6Al-4V [7]

In duplex (primary- $\alpha$ grains embedded in a lamellar $(\alpha+\beta)$ matrix) microstructures, the cooling rate from the subtransus duplex annealing temperature strongly affects the HCF performance, particularly, at low tensile mean stresses or R-ratios (Fig.9). As seen, Duplex/AC exhibits an anomalous mean stress sensitivity, i.e., the fatigue strength at $\mathrm{R}$ $=0.1$ in terms of maximum stress is not higher than the corresponding value at $\mathrm{R}=-1$ (Fig.9a). In contrast, Duplex /WQ exhibits much higher HCF strengths at $\mathrm{R}=0.1$ than at $\mathrm{R}=-1$ (Fig.9b) [7]. The low HCF strength of Duplex/AC at $\mathrm{R}=0.1$ is associated with a particular feature at the fatigue crack nucleation sites in this microstructure. Figure 10 illustrated that large facets are present at the crack nucleation site in Duplex/AC (Fig.10a). These facets correspond to similarly oriented regions in primary- $\alpha$ grains and adjacent lamellar portions which had fractured on basal or near-basal planes. Since martensitic transformation of the $\beta$-phase during water-quenching from the duplex anneal leads to a more random crystallographic orientation in the lamellar portions in Duplex/WQ, dislocation movement over longer distances is much more difficult than in Duplex/AC and no such facets were observed (Fig.10b).

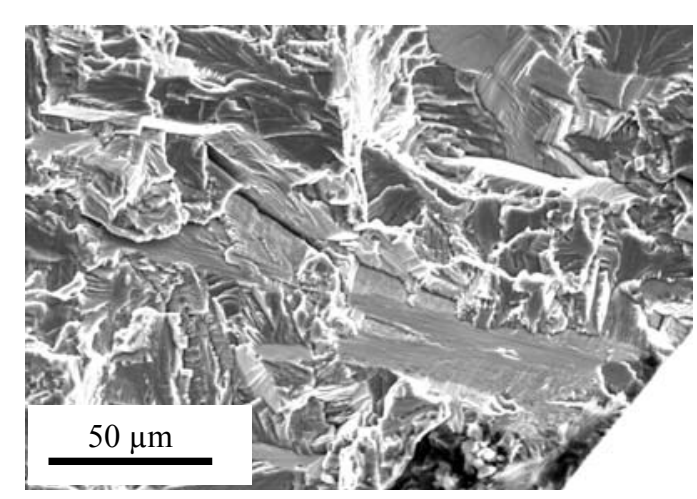

a) Duplex/AC

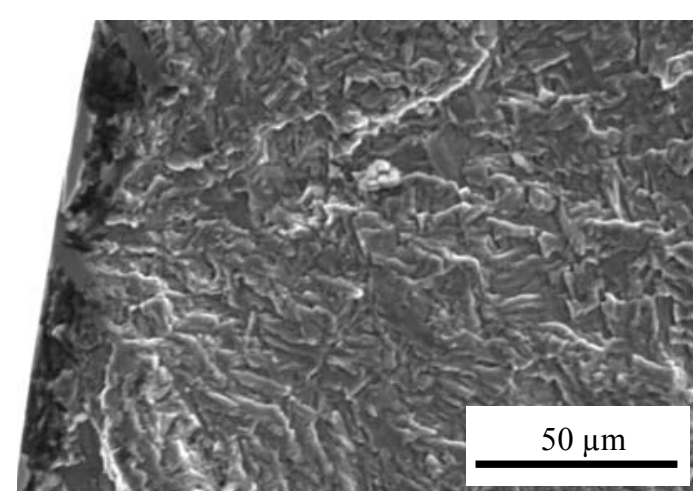

b) Duplex/WQ

Fig.10. Fatigue crack nucleation at $R=0.1$

The fatigue performance of these microstructures at $\mathrm{R}=-1$ after shot peening is shown in Figure 11. 


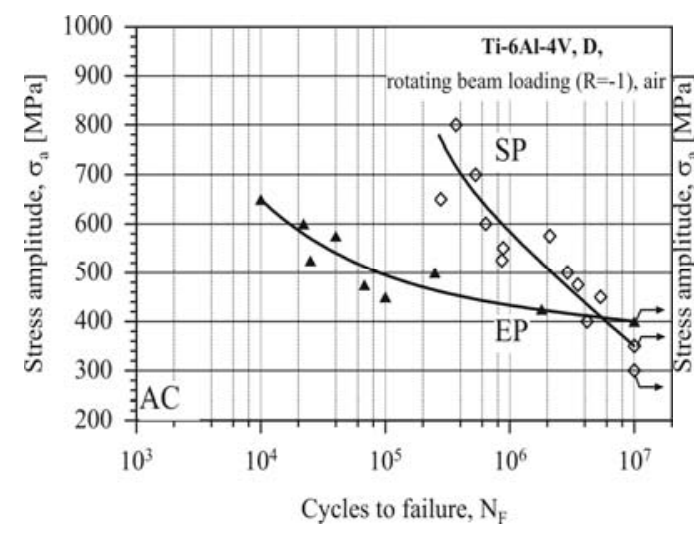

a) Duplex/AC

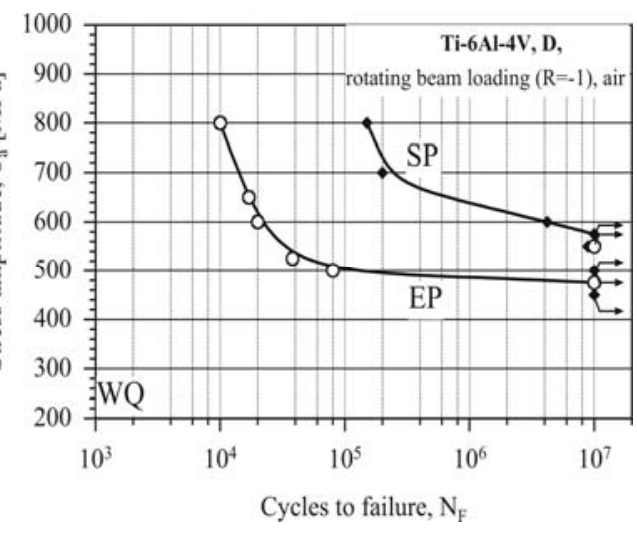

b) Duplex/WQ

Fig.11. Fatigue performance $(R=-1)$ of duplex microstructures of Ti-6Al-4V (condition SP) [8]

While there is no improvement in HCF strength after shot peening of condition D/AC (Fig.11a), the HCF strength of D/WQ (Fig.11b) is significantly improved. Since fatigue cracks were observed to have nucleated in regions of residual tensile stresses for both microstructures, the differences in the mean stress sensitivity (Fig.9) caused by the different resistances to crack nucleation (Fig.10) can explain this behavior.

\section{SUMMARY}

The shot peening-induced main changes in surface layer properties, i.e., surface topography, dislocation density and residual stresses as observed on titanium alloys are described.

In fatigue loading at high and intermediate stress amplitudes, micro-crack propagation can be drastically retarded by the process-induced residual compressive stresses resulting in an overall enhancement of fatigue life.

At low stress amplitudes, fatigue crack nucleation was observed in subsurface regions as a consequence of residual tensile stresses balancing the outer compressive stress field. The HCF response after shot peening is correlated with the tensile mean stress sensitivity of the fatigue strengths of the various microstructures.

\section{REFERENCES}

1. Schulze V.: Modern Mechanical Surface Treatments. Wiley-VCH, 2004.

2. Wagner L. and Luetjering G.: Influence of Shot Peening on the Fatigue Behavior of Ti-Alloys. Shot Peening, A. Niku-Lari [ed.], Pergamon Press, 1982, p. 453.

3. Gray H., Wagner L. and Lütjering G.: Influence of Shot Peening Induced Surface Roughness, Residual Macrostresses and Dislocation Density on the Elevated Temperature HCF-Properties of Ti-Alloys. Shot Peening, DGM, 1987. p. 447. 
4. Peters M., Luetjering G. and Jaffee R.I.: Mechanical Properties of a Titanium Blading Alloy. EPRI-Report CS-2933, Electric Power Research Institute, Palo Alto, CA, USA, 1983.

5. Wagner L.: Mechanical Surface Treatments on Titanium Alloys: Fundamental Mechanisms. Gregory J. K., Rack H. J. and Eylon D. [eds.] TMS-AIME, 1996.

6. Kocan M., Rack H.J. and Wagner L.: Considering Environmental and Mean Stress Effects in Understanding the Fatigue Performance of Shot Peened Titanium Alloys. 11th World Conf. on Titanium, Kyoto, Japan, 2007. (in press)

7. Mueller J., Rack H. J. and L. Wagner.: Effects of Supra- and Subtransus Heat Treatments on HCF Performance of Ti-6Al-4V. 11th World Conf. on Titanium, Kyoto, Japan, 2007. (in press)

8. Mueller J., Rack H. J., Ludian T. and Wagner L.: Microstructural and Mean Stress Effects in Fatigue Performance of Shot Peened Ti-6Al-4V, 11th World Conf. on Titanium, Kyoto, Japan, 2007. (in press) 